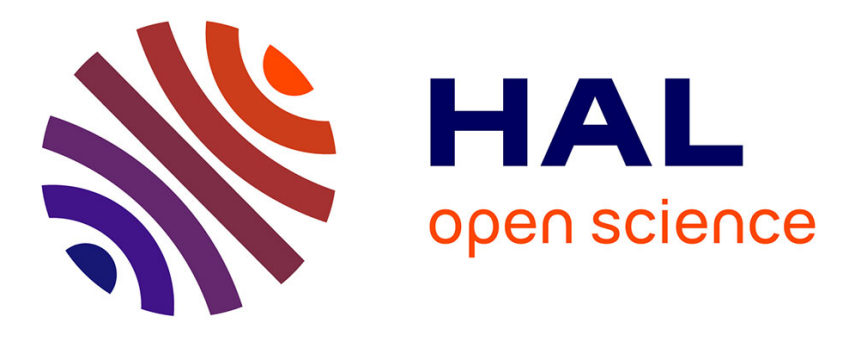

\title{
Gravimetric and dynamic deconvolution of global EQCM response of carbon nanotube based electrodes by Ac-electrogravimetry
}

Freddy Escobar-Teran, A. Arnau, J.V. Garcia, Y. Jiménez, Hubert Perrot, Ozlem Sel

\section{To cite this version:}

Freddy Escobar-Teran, A. Arnau, J.V. Garcia, Y. Jiménez, Hubert Perrot, et al.. Gravimetric and dynamic deconvolution of global EQCM response of carbon nanotube based electrodes by Ac-electrogravimetry. Electrochemistry Communications, 2016, 70, pp.73 - 77. 10.1016/j.elecom.2016.07.005 . hal-01398611

\section{HAL Id: hal-01398611 \\ https://hal.science/hal-01398611}

Submitted on 17 Nov 2016

HAL is a multi-disciplinary open access archive for the deposit and dissemination of scientific research documents, whether they are published or not. The documents may come from teaching and research institutions in France or abroad, or from public or private research centers.
L'archive ouverte pluridisciplinaire HAL, est destinée au dépôt et à la diffusion de documents scientifiques de niveau recherche, publiés ou non, émanant des établissements d'enseignement et de recherche français ou étrangers, des laboratoires publics ou privés. 


\title{
Gravimetric and Dynamic Deconvolution of Global EQCM Response of Carbon Nanotube Based Electrodes by Ac-Electrogravimetry
}

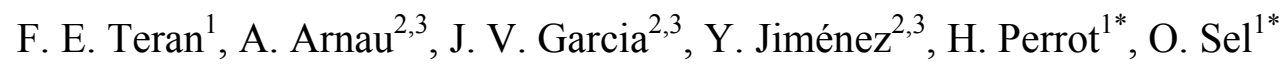

${ }^{1}$ Sorbonne Universités, UPMC Univ. Paris 06, CNRS, Laboratoire Interfaces et Systèmes Électrochimiques, 4 place Jussieu, F-75005, Paris, France.

${ }^{2}$ Polytechnic University of Valencia, Camino de Vera s/n, 46022 Valencia, Spain.

${ }^{3}$ Advanced Wave Sensors S.L., C/ Algepser 24-1, Polígono Industrial Táctica, 46980 Valencia, Spain.

* Corresponding Authors:

*ozlem.sel@upmc.fr

* hubert.perrot@upmc.fr

\begin{abstract}
The capacitive charge storage of carbon nanotube (CNT) based electrodes was investigated by $a c$-electrogravimetry which couples fast quartz crystal microbalance (QCM) and electrochemical impedance spectroscopy (EIS). In contact with an aqueous $\mathrm{NaCl}$ electrolyte, evidence was found that there are two types of cations $\left(\mathrm{Na}^{+} \cdot \mathrm{H}_{2} \mathrm{O}\right.$ and $\left.\mathrm{H}^{+}\right)$ electroadsorbed with different kinetics for cathodic potentials and the $\mathrm{Cl}^{-}$ions for anodic potentials together with free water molecules. The reconstruction of the total mass response from independent ac-electrogravimetry measurements agrees perfectly well with the global EQCM response. Our findings reveal the unique sensitivity of the $a c$-electrogravimetry to provide a fair gravimetric and dynamic deconvolution of the global EQCM responses.
\end{abstract}

Keywords: Carbon nanotubes, supercapacitors, EQCM, ac-electrogravimetry, ion transfer dynamics, electroadsorption. 


\section{Introduction}

The efficiency of energy storage devices depends largely on the physical properties of the materials that are constituted of, such as the specific surface area, porosity and/or morphology $[1,2]$.

Nanostructured carbon materials have been extensively studied as electrodes for electrochemical double layer capacitors (EDLC) [3,4]. The pore size of the carbon and its relation to the size of the ions is an important factor and should be optimized to maximize the specific capacity. Answering the questions concerning the charging mechanisms is experimentally difficult because there are not any appropriate electrochemical or physicochemical methods that allow a direct access to such information. Recent electrochemical quartz crystal microbalance (EQCM) based analyses started to address these questions [5-11]. It was successfully combined with electronic conductance studies or with nuclear magnetic resonance (NMR) to access to a full description of the electric double layer [6,9].

However, none of these methods alone provides the information on the exact identification of the electroadsorbed ionic species, their dynamics of transfer at the interfaces, as well as the role of the electrolyte composition and the effect of ions solvation on the charge storage efficiency. The dynamic aspects of ion electroadsorption inside carbon based electrodes remains a partially unsolved issue.

Here, an alternative characterization tool was proposed which couples fast quartz crystal microbalance (QCM) and electrochemical impedance spectroscopy (EIS) (also called acelectrogravimetry) [12-15]. It was employed to characterize supercapacitive charge storage mechanism of single wall carbon nanotube (SWCNT) based electrodes revealing the unique sensitivity of the $a c$-electrogravimetry to provide gravimetric and dynamic deconvolution of a global EQCM response. 


\section{Experimental}

SWCNTs were deposited by the "drop-casting" method on the gold electrode $\left(0.20 \mathrm{~cm}^{2}\right)$ of quartz crystal resonators (9 MHz-AWS, Valencia, Spain). Typically, $\sim 8 \mu \mathrm{l}$ of a solution containing $90 \mathrm{wt}$ \% SWCNT powder (length: 300-2300 nm and diameter: 0.7-1.1 nm, SigmaAldrich) and 10 wt. $\%$ PVDF-HFP polymer binder (poly(vinylidene fluoridehexafluoropropylene), Sigma-Aldrich) in N-methyl-2-pyrrolidone (NMP) was deposited using a lab-made mask. The deposited mass was estimated by measuring, $\Delta f_{m}$, before and after the deposition and by converting it to the mass change $(\Delta m)$, using the Sauerbrey equation $\left(\Delta m=-k_{s} \cdot \Delta f_{m}\right.$ where $k_{s}$ is the calibration constant $\left.\left(16.3 \times 10^{7} \mathrm{~Hz} / \mathrm{g} . \mathrm{cm}^{2}\right)\right)[16]$.

EQCM measurements were performed in aqueous $0.5 \mathrm{M} \mathrm{NaCl}$ at $\mathrm{pH}=7$ under nitrogen atmosphere. A platinum grid was used as counter electrode and $\mathrm{Ag} / \mathrm{AgCl}$ as reference electrode. The gravimetric regime was assured by keeping film thickness acoustically thin $(<500 \mathrm{~nm})$.

For $a c$-electrogravimetry, a four-channel frequency response analyzer (FRA, Solartron 1254) and a lab-made potentiostat (SOTELEM-PGSTAT) were used. The QCM was used under dynamic regime, the working electrode (WE) was polarized at a selected potential, and a sinusoidal small amplitude potential perturbation $(60 \mathrm{mV} \mathrm{rms})$ was superimposed. The microbalance frequency change, $\Delta f_{m}$, corresponding to the mass response, $\Delta m$, of the WE was measured simultaneously with the $a c$ response, $\Delta I$, of the electrochemical system. The frequency range was between $63 \mathrm{kHz}$ and $10 \mathrm{mHz}$. The resulting signals were sent to the four-channel FRA, which allowed the electrogravimetric transfer function $(\mathrm{TF}), \frac{\Delta m}{\Delta E}(\omega)$, and the electrochemical impedance, $\frac{\Delta E}{\Delta I}(\omega)$, to be simultaneously obtained at a given potential [12-15]. The measurements were performed in $0.5 \mathrm{M} \mathrm{NaCl}$ at $\mathrm{pH}=7$ and at every $100 \mathrm{mV}$ in the following potential range: $-0.45 \mathrm{~V}-0.45 \mathrm{~V} v \mathrm{Ag} / \mathrm{AgCl}$. 


\section{Theoretical Background}

For supercapacitive SWCNT thin films, the change of the concentration, $\Delta C_{i}$, of each species (e.x. $i=$ cation 1 (c1) and cation 2 (c2), and free solvent (s)) over a potential $\Delta E$ step can be estimated using Eq. (1):

$$
\left.\frac{\Delta C_{c_{i}}}{\Delta E}\right|_{t h}(\omega)=-\frac{G_{c_{i}}}{\left(j \omega d_{f}\right)+K_{c_{i}}}
$$

where $\omega=2 \pi \mathrm{f}$ is the pulsation, $d_{f}$ is the film thickness and $K_{i}$ and $G_{i}$ are the partial derivatives of the flux, $J_{i}$, with respect to the concentration and the potential, respectively. $K_{i}$ is related to the kinetics of the ionic or free solvent transfer. $G_{i}$ is the inverse of the transfer resistance, $R t_{i}=\frac{1}{F G_{i}}$, of the species at the film/electrolyte interface [12-15].

The charge/potential TF, $\left.\frac{\Delta q}{\Delta E}\right|_{t h}(\omega)$, is calculated for the electroadsorption of the two cations (as an example), $\mathrm{c} 1$ and $\mathrm{c} 2$ by using the Faraday number, $F$, and the film thickness, $d_{f}$ :

$$
\left.\frac{\Delta q}{\Delta E}\right|_{t h}(\omega)=F d_{f}\left(\frac{G_{c 1}}{j \omega d_{f}+K_{c 1}}+\frac{G_{c 2}}{j \omega d_{f}+K_{c 2}}\right)
$$

The electrogravimetric TF, $\left.\frac{\Delta m}{\Delta E}\right|_{t h}(\omega)$, can be calculated theoretically, taking into account the charged and uncharged species contribution through the two parameters $K_{s}$ and $G_{s}$ :

$$
\left.\frac{\Delta m}{\Delta E}\right|_{t h}(\omega)=-d_{f}\left(m_{c 1} \frac{G_{c 1}}{\left(j \omega d_{f}\right)+K_{c 1}}+m_{c 2} \frac{G_{c 2}}{\left(j \omega d_{f}\right)+K_{c 2}}+m_{s} \frac{G_{s}}{\left(j \omega d_{f}\right)+K_{s}}\right)
$$


where $\mathrm{m}_{\mathrm{c} 1}, \mathrm{~m}_{\mathrm{c} 2}$, and $\mathrm{m}_{\mathrm{s}}$ are the atomic weight of involved species.

\section{Results and Discussion}

Electrochemical performance of SWCNT based thin films was characterized in a classical manner via cyclic electrogravimetry in $0.5 \mathrm{M}$ aqueous $\mathrm{NaCl}$. Figure $1 \mathrm{~A}$ shows quasirectangular shaped cyclic voltammetry $(\mathrm{CV})$ responses indicating that the charge storage is mainly due to the reversible electroadsorption of the ions which is in good agreement with the results of the similar systems [11]. The corresponding mass variations is followed by simultaneous QCM measurements as a function of potential (Fig. 1B). Figure 1B presents a change in slope around $0.1 \mathrm{~V} v s \mathrm{Ag} / \mathrm{AgCl}$ where $\frac{\Delta \mathrm{m}}{\Delta \mathrm{E}}\left\langle 0\right.$ and $\left.\frac{\Delta \mathrm{m}}{\Delta \mathrm{E}}\right\rangle 0$ for the transfer of cations and the anions, respectively. It indicates that the point of zero charge (PZC) is around this value. To obtain indications on the nature of the transferred species, the $F \times \frac{\Delta m}{\Delta q}=F \frac{\Delta m / \Delta t}{\Delta Q / \Delta t}$ function was calculated from the EQCM data (Fig. 1A,B) which corresponds to the molar mass of the species exchanged at the electrode/electrolyte interfaces at a given scan rate. Figure 1C shows that the estimated molar mass values are between 23 and 40 g.mol ${ }^{-1}$ in the potential range from $0.4 \mathrm{~V}$ to $0.05 \mathrm{~V}$ vs $\mathrm{Ag} / \mathrm{AgCl}$. The higher values suggest that the cations are hydrated and/or accompanied by free solvent molecules. The contribution of $(i)$ counter ions solely, (ii) counter ions and solvent or (iii) both counter- and co-ions (without solvent) in carbon based electrodes were intensively investigated by Levi and Aurbach et al. [10], and similar cases were considered in doped conducting polymers and conventional redox systems by Bruckenstein and Hillman et al. [17-20]. 
Our findings and the literature results strongly suggest that the EQCM data envelops the subtleties of the supercapacitive charge storage. This global EQCM response, measured at a certain scan rate cannot give an easy access to the details related to the capacitive charge storage mechanism. Therefore, an ac-electrogravimetric study is conducted for the deconvolution of the global EQCM response into distinct contributions with a resolution at the temporal level.

Fig. $2 \mathrm{~A}$ and $2 \mathrm{~B}$ present $\frac{\Delta q}{\Delta E}(\omega)$ and $\frac{\Delta m}{\Delta E}(\omega)$ transfer functions (TFs) (at $-0.4 \mathrm{~V}$ ) where the experimental data are fitted using Eq. 2 and 3, respectively (details of the model in Ref. 1215). For fitting the experimental data, several configurations were considered involving $\mathrm{Na}^{+}$, $\mathrm{H}^{+}$, their hydrated counterparts and free $\mathrm{H}_{2} \mathrm{O}$ with the strict criteria that a good agreement between the experimental and the theoretical function in terms of shape and frequencies was achieved. Figure $2 \mathrm{~B}$ depicts an example of a mass/potential $\mathrm{TF}$ where the three species participate to the electroadsorption process, i.e. $\mathrm{Na}^{+} \cdot \mathrm{H}_{2} \mathrm{O}, \mathrm{H}^{+}$and free $\mathrm{H}_{2} \mathrm{O}$ (no anion contribution is expected at $-0.4 \mathrm{~V})$. The partial mass/potential TFs were also analyzed to validate our hypothesis involving three different species; they are estimated, for example by removing the c2 contribution, calculating $\left.\frac{\Delta m}{\Delta E}\right|_{t h} ^{c l s}$ or by removing the c1 contribution, calculating $\left.\frac{\Delta m}{\Delta E}\right|_{t h} ^{c 2 s}$ (not shown). The hydrated $\mathrm{Na}^{+}$appears at high frequency (fast process) whereas the protons participate at low frequency (slow process). The kinetics of the free solvent molecules is close to that of hydrated $\mathrm{Na}^{+}$species suggesting that polar water molecules are electrodragged together with hydrated $\mathrm{Na}^{+}$.

As the measurements were performed over the potential, $K_{i}$ (kinetics of transfer) and $G_{i}$ (related to the ease of interfacial transfer) parameters were also estimated at different potential values (Fig. 2C and 2D). Two different cationic species and free water molecules were 
detected in the potential range from $-0.4 \mathrm{~V}$ to $0 \mathrm{~V}$ (no major anions contribution in that region). The hydrated $\mathrm{Na}^{+}$ions are persistently the fastest species, i.e. $\left.K_{i}\left(\mathrm{Na}^{+} . \mathrm{H}_{2} \mathrm{O}\right)\right\rangle K_{i}\left(\mathrm{H}^{+}\right)$) (Fig. 2C). The $G_{i}$ parameter permits the $R t_{i}$ (transfer resistance) to be calculated which can explain the ease or the difficulty in the transfer at the electrode/electrolyte interface. The $R t_{i}$ values present the following order: $R t_{i}\left(H^{+}\right)>R t_{i}\left(N a^{+} . H_{2} \mathrm{O}\right)$ (inverse of the $\left.K_{i}\right)$.

These findings strongly suggest that $\mathrm{Na}^{+} \cdot \mathrm{H}_{2} \mathrm{O}$, although formally larger than $\mathrm{H}^{+}$, are faster and easier to be electroadsorbed at the SWCNT/electrolyte interfaces. This, a priori anomalous behavior can be discussed in terms of cation concentration or of the relationship between the dehydration energy and the ion size. For the former, the proton concentration is lower compared to the sodium and can affect the kinetics of transfer. For the latter, the smaller ions are more tightly bound to their water molecules such that it exists an inverse relationship between the dehydration energy and the ion size [21-23]. Additionally, the possibility that electroadsorption occurs in two different sites; directly on the surface (sites more accessible for the hydrated sodium) or inside the nanotubes (sites less accessible for the dehydrated protons) can be suggested.

The participation of the anions $\left(\mathrm{Cl}^{-}\right)$to the electroadsorption process was also detected at around the PZC (Fig. 2C,D) probably due to the permselectivity failure of the SWCNT films around this value leading to the mixed adsorption [7]. Their transfer resistance is high around PZC which decreases at more anodic potentials i.e. $0.4 \mathrm{~V}$ vs $\mathrm{Ag} / \mathrm{AgCl}$.

A major advantage of $a c$-electrogravimetry is the estimation of the relative concentration change with respect to the individual species (after integration of $\left.\frac{\Delta C_{i}}{\Delta E}\right)_{\omega \rightarrow 0}=-\frac{G_{i}}{K_{i}}, C_{i}-C_{0}$ values can be determined) $[12,13]$. It is noteworthy that despite the slow kinetics and high transfer resistance of the protons, their contribution to the charge storage is not negligible 
(Fig. 3A). For more anodic potentials (when the SWCNT surface is positively charged), the electroadsorption of anions occurs keeping the electroneutrality of the electrode/electrolyte interface.

The concentration variation of individual species $\left(C_{i}-C_{0}\right)$ obtained from the $a c$ electrogravimerty are converted into their respective mass variations (Fig. 3B). Subsequently, the total mass response of the SWCNT electrode is reconstructed by addition of the individual contributions (Fig. 3C) which agrees perfectly well with the global EQCM results (Fig. 3D) (i.e. $\Delta m_{\text {ac-electrogravimetry }}=0.65 \mu \mathrm{g} \cdot \mathrm{cm}^{-1}$ and $\Delta m_{E Q C M}=0.62 \mu \mathrm{g} \cdot \mathrm{cm}^{-1}$ for the cathodic potentials). It is further highlighted that ac-electrogravimetry results are obtained from individual measurements at stationary potentials and the reconstructed mass response is in good agreement with the EQCM data from cyclic voltammetry. This is highly significant since it evidences that the ac-electrogravimetry result in Fig. 3B is indeed a deconvolution of the global EQCM mass response into distinct contributions. Since ac-electrogravimtery provides additional information on the kinetics of the respective species, then it is legitimate to call it a gravimetric and dynamic deconvolution.

\section{Conclusions}

The contribution of two cations $\left(\mathrm{Na}^{+} \cdot \mathrm{H}_{2} \mathrm{O}\right.$ and $\left.\mathrm{H}^{+}\right)$and an anion $\left(\mathrm{Cl}^{-}\right)$were detected when the SWCNT electrode surface is negatively and positively charged, respectively. The deconvolution of the global EQCM response into distinct contributions (identification of ions, solvation numbers and free solvent contributions) and the kinetics of electroadsorption are the strong assets of the ac-electrogravimetry which cannot be attained via EQCM alone. The methodology can be extended to characterize other carbon based electrodes and pave the way toward more performant electrode/electrolyte systems in energy storage. 
Acknowledgements: F. E. acknowledges SENESCYT for financial support. F. Pillier and S. Casale are thanked for the FEG-SEM and HRTEM measurements, respectively.

\section{References}

[1] P. Simon, Y. Gogotsi, Materials for electrochemical capacitors, Nature Mater. 7 (2008) $845-854$

[2] J. R. Miller, P. Simon, Materials science. Electrochemical capacitors for energy management, Science 321 (2008) 651-652.

[3] P. Simon, Y. Gogotsi, Capacitive energy storage in nanostructured carbon-electrolyte systems, Acc. Chem. Res. 46 (2012) 1094-1103.

[4] F. Beguin, V. Presser, A. Balducci, E. Frackowiak, Carbons and electrolytes for advanced supercapacitors, Adv. Mater. 26 (2014) 2219-2251.

[5] M. D. Levi, G. Salitra, N. Levy, D. Aurbach, J. Maier, Application of a quartz-crystal microbalance to measure ionic fluxes in microporous carbons for energy storage, Nature Mat. 9 (2009) 872-875.

[6] S. Sigalov, M. D. Levi, G. Salitra, D. Aurbach, J. Maier, EQCM as a unique tool for determination of ionic fluxes in microporous carbons as a function of surface charge distribution, Electrochem Comm. 12 (2010) 1718-1721.

[7] M. D. Levi, S. Sigalov, D. Aurbach, L. Daikhin, In-situ electrochemical quartz crystal admittance methodology for tracking compositional and mechanical changes in porous carbon electrodes, J. Phys. Chem C 117 (2013) 14876-14889. 
[8] W-Y. Tsai, P. L. Taberna, S. Patrice, Electrochemical quartz crystal microbalance (EQCM) study of ion dynamics in nanoporous carbons, J. Am. Chem. Soc. 136 (2014) 87228728.

[9] J. M. Griffin, A. C. Forse, W-Y. Tsai, P-L. Taberna, P. Simon, C. P. Grey, In situ NMR and electrochemical quartz crystal microbalance techniques reveal the structure of the electrical double layer in supercapacitors, Nature Mat. 14 (2015) 812-820.

[10] M. D. Levi, S. Sigalov, G. Salitra, D. Aurbach, J. Maier, The effect of specific adsorption of cations and their size on the charge-compenstaion mechanism in carbon micropores: the role of anion desorption, Chem Phys Chem 12 (2011) 854-862.

[11] M. D. Levi, S. Sigalov, G. Salitra, D. Aurbach, Quartz crystal microbalance with dissipation monitoring (EQCM-D) for in-situ studies of electrodes for supercapacitors and batteries: A mini-review, Electrochem. Commun. 67 (2016) 16-21.

[12] C. Gabrielli, J. Jareno, M. Keddam, H. Perrot, F. Vicente, Ac-Electrogravimetry study of electroactive thin Films. I. Application to prussian blue, J. Phys. Chem. B, 106 (2002) 31823191.

[13] C. Gabrielli, J. Jareno, M. Keddam, H. Perrot, F. Vicente, Ac-Electrogravimetry study of electroactive thin films. II. Application to polypyrrole, J. Phys. Chem. B, 106 (2002) 31923201.

[14] C. Ridruejo Arias, C. Debiemme-Chouvy, C. Gabrielli, C. Laberty-Robert, A. Pailleret, H. Perrot, O. Sel, New insights into pseudocapacitive charge-storage mechanisms in LiBirnessite type $\mathrm{MnO}_{2}$ monitored by fast quartz crystal microbalance methods, J. Phys. Chem C 118 (2014) 26551-26559.

[15] F. Razzeghi, C. Debiemme-Chouvy, F. Pillier, H. Perrot O. Sel, Ion intercalation dynamics of electrosynthesized mesoporous $\mathrm{WO}_{3}$ thin films studied by multi-scale coupled electrogravimetric methods, Phys. Chem. Chem. Phys. 17 (2015) 14773-14787. 
[16] G. Sauerbrey, Verwendung von Schwingquarzen zur wagung dunner Schicten un zur Mikrowagung, Z. Angew. Phys. 155 (1959) 206-222.

[17] A. R. Hillman, M. A. Mohamoud, S. Bruckenstein, Modelling mobile species dynamics within electroactive films under mixed thermodynamics and kinetic control, Electroanalysis 17 (2005) 1421-1432.

[18] S. Bruckenstein, K. Brzezinska, A. R. Hillman, EQCM studies of polypyrrole films. 1. Exposure to aqueous sodium tosylate solutions under thermodynamically permselective conditions, Electrochim. Acta 45 (2000) 3801-3811.

[19] S. Bruckenstein, K. Brzezinska, A. R. Hillman, EQCM studies of polypyrrole films. Part 2. Exposure to aqueous sodium tosylate solutions under thermodynamically nonpermselective conditions, Phys. Chem. Chem. Phys. 2 (2000) 1221-1229.

[20] M. Skompska, A. R. Hillman, Electrochemical quartz crystal microbalance studies of the electrodeposition and subsequent cross-linking of poly(N-vinylcarbazole) films, J. Electroanal. Chem. 433 (1997) 127-134.

[21] I. Waluyo, C. Huang, D. Nordlund, U. Bergmann, T. M. Weiss, G. M. Petterson, A. Nilsson, The structure of water in the hydration shell of cations from x-ray Raman and small angle x-ray scattering measurements, J. Chem. Phys. 134 (2011) 064513-064516.

[22] R. MacKinnon, Potassium Channels and the Atomic Basis of Selective Ion Conduction, Angew. Chemie Int. Ed. 43 (2004) 4265-4277.

[23] Y. F. Zhou, J. H. Morais-Cabral, A. Kaufman, R. MacKinnon, Chemistry of ion coordination and hydration revealed by a $\mathrm{K}^{+}$channel-Fab complex at 2.0 Å resolution, Nature $414(2001) 43-48$. 
Figure Captions

Fig. 1 The CV curves (A), the simultaneous mass responses (B) and the $F \times \frac{\Delta m}{\Delta q}$ function (C) of the SWCNT based thin films in $0.5 \mathrm{M} \mathrm{NaCl}$ at $\mathrm{pH}=7$.

Fig. $2 \frac{\Delta q}{\Delta E}(\omega)(\mathrm{A})$ and $\frac{\Delta m}{\Delta E}(\omega)(\mathrm{B})$ at $-0.4 \mathrm{~V} v s \mathrm{Ag} / \mathrm{AgCl}$, kinetic parameters $K_{i}\left(\mathrm{~cm} . \mathrm{s}^{-1}\right)(\mathrm{C})$, and the transfer resistance values, $R_{t i}\left(\Omega . \mathrm{cm}^{2}\right)$ (D) of the SWCNT based thin films as a function of potential in $0.5 \mathrm{M} \mathrm{NaCl}$ at $\mathrm{pH}=7$.

Fig. 3 Relative concentration variation, $C_{i}-C_{0}$ (A), relative mass variation (B) (calculated from A) of respective species in the SWCNT based electrode, measured in $0.5 \mathrm{M} \mathrm{NaCl}$ at $\mathrm{pH}=7$. Total mass variation reconstructed from $a c$-electrogravimerty $(\mathrm{C})$ is compared with the EQCM data (D). 
Figures

A

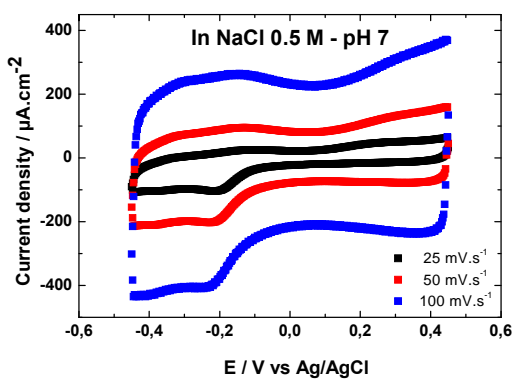

B

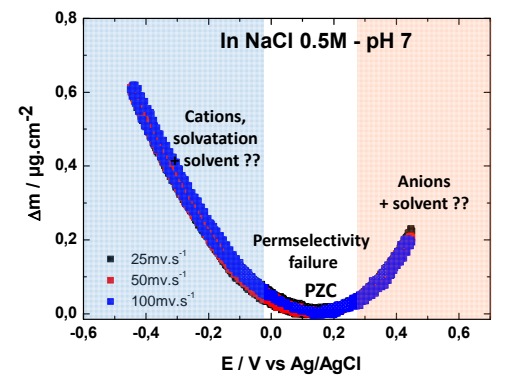

C

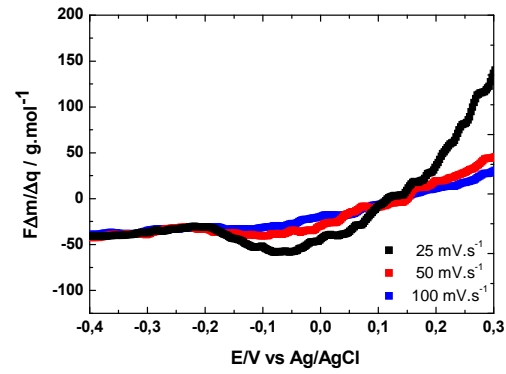

Fig. 1 
A

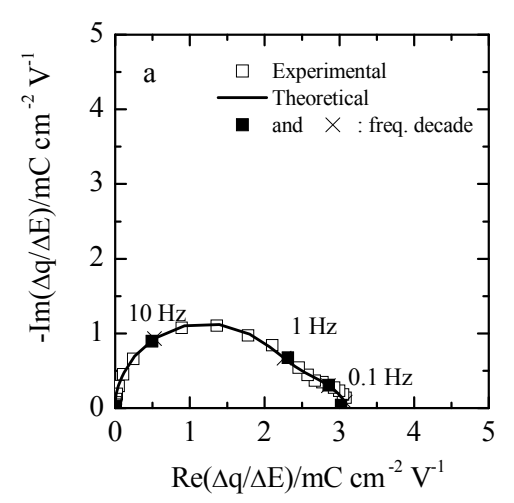

C

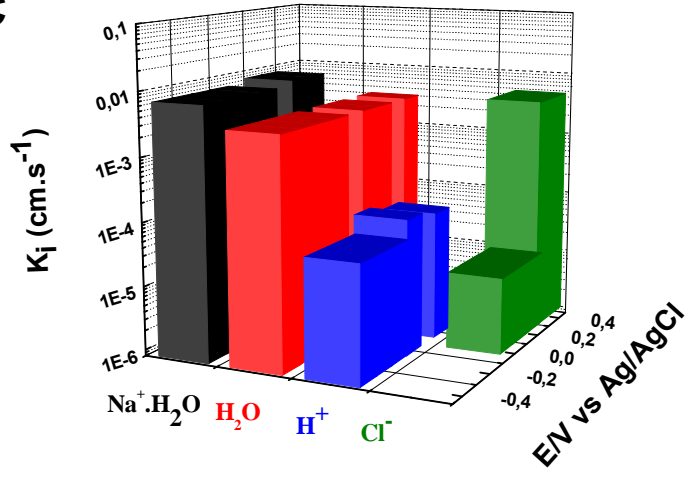

B

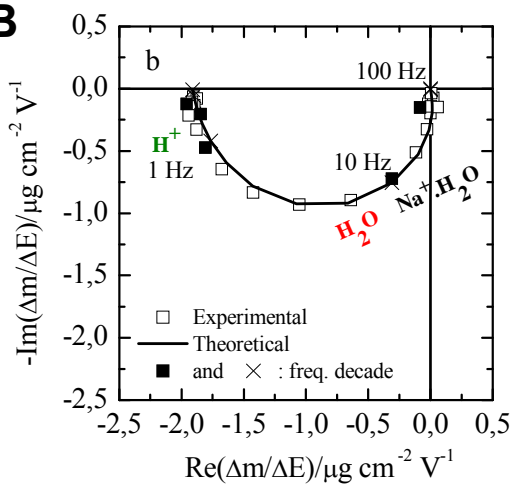

D

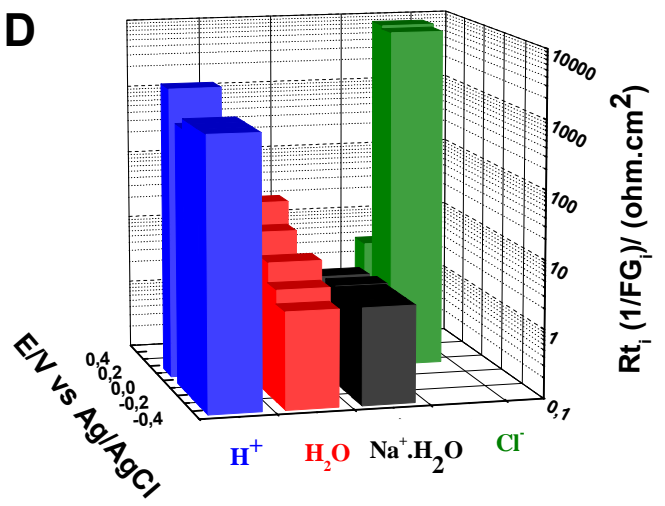

Fig. 2 
A
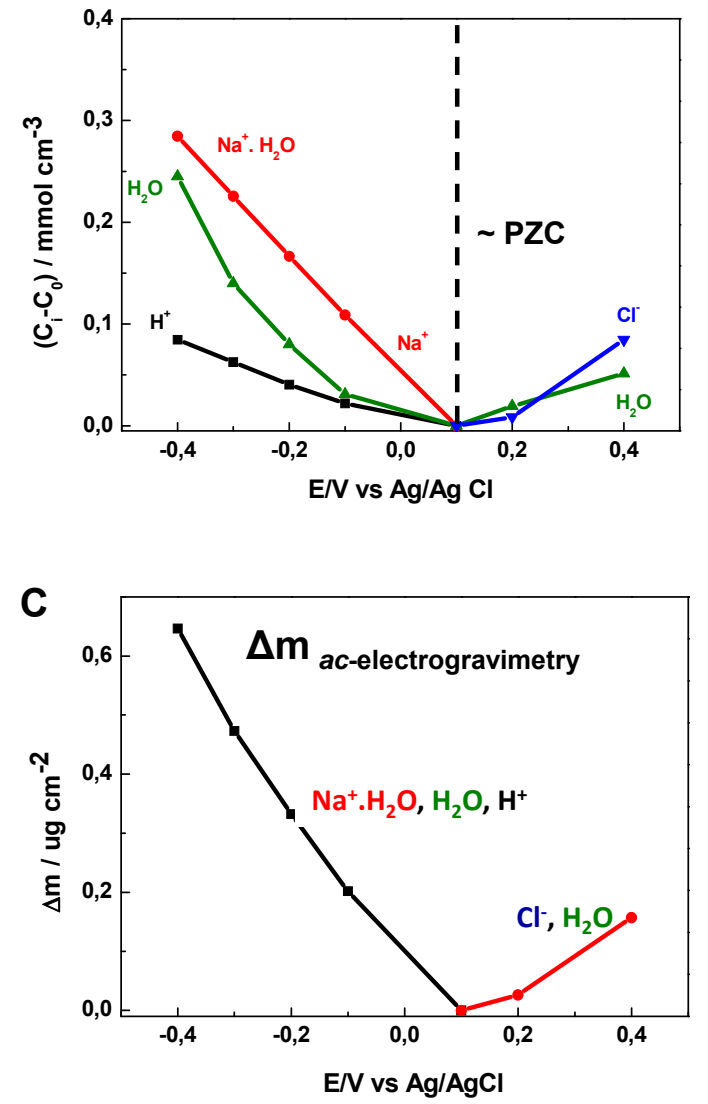

B
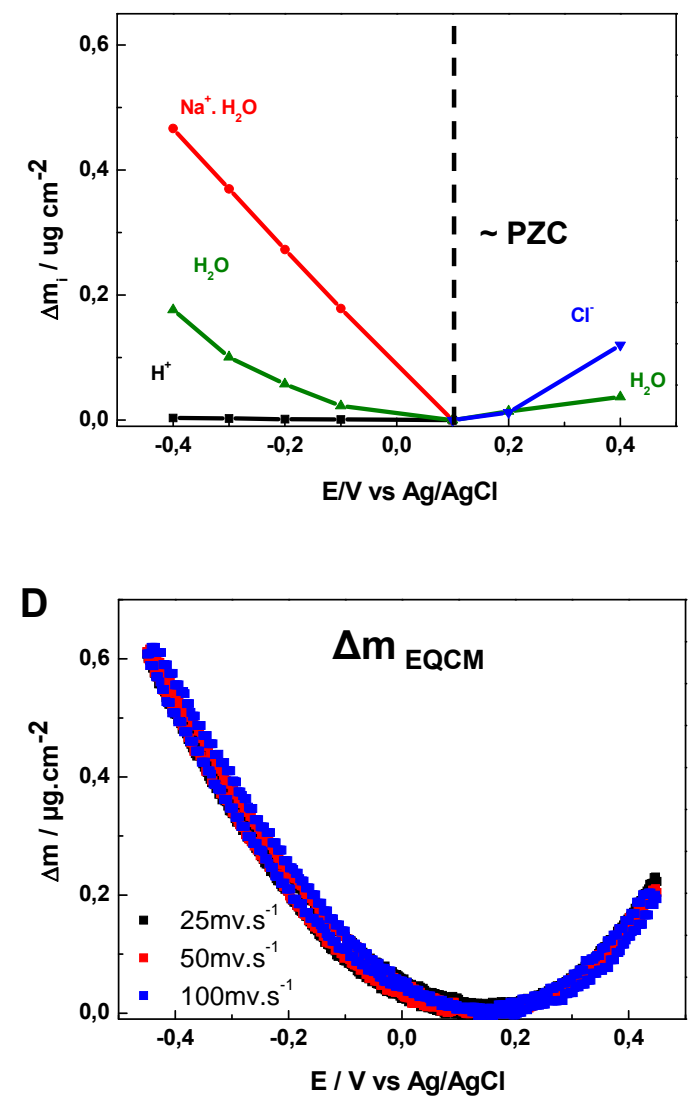

Fig. 3 